\title{
Da redação aos blogs: a busca por novos arranjos econômicos e alternativas ao trabalho jornalístico ${ }^{1}$
}

\section{From writing to blogs: the search for new economic and alternative journalistic work arrangements}

\author{
Cláudia Nonato \\ FIAM-FAAM Centro Universitário \\ <claudia.nonato@uol.com.br>
}

\section{RESUMO}

Este artigo é baseado na pesquisa Jornalistas, blogueiros, migrantes da comunicação: em busca de novos arranjos econômicos para o trabalho jornalístico com maior autonomia e liberdade de expressão (LIMA, 2015), realizada a partir da proposta teóricometodológica de aproximação entre Comunicação e Trabalho, sob a perspectiva da Teoria do Valor (Marx) e da Ergologia (Schwartz). Tal abordagem se justifica pelo fato de a comunicação ser fundamento da atividade humana e dos processos de trabalho. Desse modo, a pesquisa buscou comprovar duas hipóteses: a) os profissionais do jornalismo com vasta experiência na profissão estão migrando para novas mídias, principalmente para blogs independentes; $b$ ) jornalistas experientes migram para os blogs em busca de maior autonomia, liberdade de expressão e realização profissional. Para chegar aos resultados, foram analisadas as entrevistas e rotinas de produção de 15 jornalistas blogueiros, separados metodologicamente entre dependentes e independentes (de veículos de comunicação).

Palavras-chave: Jornalistas blogueiros. Blogosfera. Arranjos econômicos alternativos.

\begin{abstract}
This article is based on the research Journalists, bloggers, and communication migrants: in search of new economic arrangements for the journalistic work with greater autonomy and freedom of expression (LIMA, 2015), based on the theoretical-methodological approach of Communication and Work, from the perspective of Value Theory (Marx) and Ergology (Schwartz). Such an approach is justified by the fact that communication is the foundation of human activity and work processes. The research sought to prove two hypotheses: a) journalism professionals with vast experience in the profession are migrating to new media, especially for independent blogs; B) experienced journalists migrate to blogs in search of greater autonomy, freedom of expression and professional achievement. To reach the results, it were analyzed the interviews and production routines of 15 journalist bloggers, methodologically separated between dependents and independent (of communication vehicles).
\end{abstract}

Keywords: Journalists bloggers. Blogosphere. Alternative economic arrangements.

\section{Introdução}

O mundo do trabalho é peça fundamental para o estudo de diversas faces das relações humanas; lugar de mediação e de construção de subjetividade. É espaço de relações interpessoais, de troca de sociabilidades, identidades e

1 Pesquisa financiada pela Coordenação de Apoio ao Ensino Superior - CAPES 
autoestima. E, ao discutirmos e ampliarmos o conceito de trabalho, podemos analisá-lo como atividade humana, o que nos permite, a partir da perspectiva Ergológica (Schwartz, 2003), problematizar o objeto de estudo de maneira mais complexa, destacando a relevância dos sujeitos na transformação social (Figaro, 2012). Nesta perspectiva, reconhecer o trabalho como atividade humana significa romper a visão positivista e que entende o trabalho apenas como racionalidade técnica, restrito, nas sociedades capitalistas, ao conceito de emprego ou de profissão.

Comunicação e trabalho é um binômio criado para ressaltar o aspecto ontológico que ambos os conceitos partilham, e para permitir aos pesquisadores do campo da Comunicação indagar como as mudanças econômicas, tecnológicas e culturais são identificadas pelas relações de comunicação no mundo do trabalho. É nesse "mundo" que as transformações se dão com maior intensidade, o trabalho adquire outros sentidos, os processos de comunicação para a organização da produção se diversificam e influenciam as transformações nas formas de trabalhar e de se relacionar socialmente.

Desta forma, recusamos a simplificação que trata a comunicação como sinônimo de transmissão de informação, como mídia ou dispositivo tecnológico, hipótese teórica que nos permite estudar as relações de comunicação no mundo do trabalho e, em nosso caso específico, como os jornalistas têm enfrentado os desafios profissionais na sociedade contemporânea. Neste texto, resultado de uma pesquisa de doutoramento, Jornalistas, blogueiros, migrantes da comunicação: em busca de novos arranjos econômicos para o trabalho jornalístico com maior autonomia e liberdade de expressão (Lima, 2015), detalhamos nossas hipóteses de estudo, o objeto de nossas questões e a metodologia adotada para auxiliar na elaboração da tese. Em seguida, esclarecemos os principais pressupostos conceituais que balizam nossa abordagem de comunicação e trabalho no tratamento dos jornalistas migrantes da comunicação, para finalizarmos com os discursos e conclusões da pesquisa.

\section{Objeto de estudo e metodologia}

O objeto de estudo da pesquisa são os jornalistas blogueiros. A partir desse grupo, a pretensão era comprovar as seguintes hipóteses: a) os profissionais do jornalismo com vasta experiência na profissão estão migrando para novas mídias, principalmente para blogs independentes; e b) jornalistas experientes migram para os blogs em busca de maior autonomia, liberdade de expressão e realização profissional. 
Diante da observação, levantamento documental e bibliográfico, foi constatado que a maior parte das categorizações acadêmicas feitas até aqui partiram do blog como referência e distinção, e não do blogueiro como objeto central. Desse modo, foi criada, para melhor condução da pesquisa, uma nova categorização, baseada na raiz econômica da questão. A partir da tipologia sugerida por Primo (2010), blogs jornalísticos foram considerados como "profissionais reflexivos" e os blogueiros divididos em duas categorias: dependentes (A) e independentes (B), sendo que os primeiros possuíam blogs vinculados a portais, como funcionários ou contratados de grandes grupos de comunicação; e os independentes dividiam-se em duas subcategorias, ligados ou não a portais.

Desse modo, além de selecionar os blogueiros pela carreira bem consolidada a opção foi por utilizar também como critério - após quatro anos de acompanhamento e observação - os blogueiros considerado mais ativos, citados e compartilhados em redes sociais, mesclando no grupo selecionado jornalistas contratados por empresas de comunicação e independentes. $O$ corpus final reuniu um total de quinze jornalistas: Josias de Souza, Juca Kfouri, Leonardo Sakamoto, Reinaldo Azevedo, Ricardo Kotscho e Ricardo Noblat (categorizados como dependentes - ligados a portais de grandes grupos de comunicação); Conceição Oliveira, Renato Rovai, Rodrigo Vianna, Luís Nassif, Luiz Carlos Azenha e Paulo Henrique Amorim (categorizados como independentes e ligados a portais também independentes); Altamiro Borges, Altino Machado e Miguel do Rosário (independentes e sem ligação com portais). Vale destacar que, em relação ao gênero, o número de jornalistas do sexo feminino é pequeno, em comparação à quantidade de representantes do sexo masculino.

Além disso, as opções metodológicas estão diretamente ligadas às fundamentaçõesteóricas, queforamarticuladasa partirdashipótesesformuladas. Desse modo, foi utilizada também a análise documental, que compreende, segundo Moreira (2015, p. 272), "a identificação, a verificação e a apreciação de documentos para determinado fim". Portanto, embora não seja tradicional no campo da comunicação, o método foi considerado adequado para este trabalho, por utilizar no resgate histórico dos meios de comunicação, "personagens ou períodos e fontes como acervos de impressos, documentos oficiais, técnicos ou pessoais" (Moreira, 2015, p. 272). A segunda etapa da categorização serviu para visualizar onde realmente estão os blogueiros independentes (do ponto de vista econômico) e, dentro desse grupo, coletar as entrevistas.

O grupo foi considerado representativo para demonstrar as mudanças que ocorreram no jornalismo contemporâneo em decorrência da internet e das redes sociais. Estes jornalistas migraram para o novo meio com uma carreira 
já consolidada nos veículos tradicionais, conseguiram manter o seu público e ainda conquistaram novos leitores. Para dar relevância necessária ao objeto de estudo, serão discutidos no artigo temas articulados à questão econômica, eixo da pesquisa, a partir da globalização e suas consequências para a Comunicação e para o mundo do trabalho.

\section{A globalização e a reestruturação produtiva do mundo do trabalho}

Para Wolton (2012), o sistema técnico, o modelo cultural dominante e a organização econômica são fundamentais para compreender o lugar e o papel da comunicação. Desse modo, as mudanças que ocorreram na sociedade a partir das invenções advindas da Revolução Industrial (século XXIII) foram principalmente sociais, culturais e técnicas. A globalização afetou não só os modos de produção dos produtos comunicacionais, como também os profissionais e as rotinas da área da Comunicação. Ou, como afirma Ortiz, "os meios de comunicação contêm uma dimensão que transcende suas territorialidades" (2000, p. 60).

A partir desses eventos, o trabalho humano foi substituído pelas máquinas; as relações entre capital e trabalho se acirram e surge a chamada Cultura de Massa. Briggs e Burke (2006, p. 112) afirmam que a Revolução Industrial e a "revolução da comunicação" podem ser vistas como parte de um mesmo processo. Os autores tratam a chegada do vapor como ponto de partida para acelerar o ritmo das transformações não só tecnológicas, mas também industriais; mudanças que radicalizaram a luta de classes. Contam ainda que, embora Karl Marx tenha visto a invenção do motor a vapor como "o grande marco da história humana, separando o passado do presente e descortinando um futuro revolucionário" (2006, p. 115), para ele, a verdadeira revolução viria da luta de classes entre capitalistas e proletariado, e não por meio da tecnologia.

A globalização também atinge a Comunicação a partir da proliferação de canais de comunicação e de difusão da informação, e da emergência dos monopólios, que começam a se formar no final do século XIX e se transformaram em grandes empresas, corporações e conglomerados multinacionais (Thompson, 2014). Esse crescimento levou a desigualdades que, segundo o autor, beneficiaram "mais a uns do que a outros, e que incluiu mais rapidamente algumas partes do mundo nas redes de comunicação global do que outras" (Thompson, 2014, p. 208).

Além da propagação dos meios de comunicação, ocorre durante a globalização uma reorganização produtiva do trabalho, principalmente a partir do século XX, época em que o capitalismo entra em nova fase monopolista e financeira. A intensificação do trabalho e o aumento da produção levaram à 
criação e à introdução de novas formas de racionalização do processo produtivo, que redefiniram a velocidade e o ritmo imposto ao trabalho: o taylorismo, o fordismo e, mais tarde, o toyotismo. Tais métodos foram adaptados ao Ocidente principalmente a partir da década de 1980, época em que ocorreram profundas transformações no mundo do trabalho de países de capitalismo avançado, trazendo para a sociedade contemporânea a chamada reestruturação produtiva. Essas modificações abalaram não só a materialidade, como a subjetividade da classe-que-vive-do-trabalho, mas também a sua forma de ser (Antunes, 1995). Além disso, essa flexibilização da organização do trabalho traz consequências diretas na percepção da compressão do espaço-tempo (Harvey, 1996) social.

Para Antunes, essas novas configurações trouxeram à tona uma velha modalidade de trabalho, o precário, "com o objetivo de recuperar as formas econômicas, políticos e ideológicas da dominação burguesa" (1995, p. 233). Nos dias atuais, o trabalho precário surge como "empreendedorismo", "cooperativismo" e "trabalho voluntário", entre outros. E, entre as diferentes formas de flexibilização imposta pelas empresas destacam-se, para o autor, "a salarial, de horário, funcional ou organizativa".

\section{A reestruturação das redações}

Ao descrever as novas relações trabalhistas impostas pela reestruturação produtiva, que atingiu e ainda atinge a todas as áreas, nos aproximamos da realidade dos jornalistas. Duas pesquisas realizadas recentemente no Brasil comprovam essa mudança. A primeira, intitulada $O$ perfil do jornalista e os discursos sobre o jornalismo - um estudo das mudanças no mundo do trabalho do jornalista profissional em São Paulo (Figaro, 2012), foi realizada entre 2009 e 2012 na Universidade de São Paulo por pesquisadores do Centro de Pesquisa em Comunicação eTrabalho (CPCT-ECA/USP). A segunda pesquisa, Perfildo jornalista brasileiro - Características demográficas, políticas e do trabalho jornalístico (Mick, 2012), foi feita por pesquisadores do Núcleo de Estudos sobre Transformações no Mundo do Trabalho, da Universidade Federal de Santa Catarina (TMT/UFSC), em convênio com a Federação Nacional dos Jornalistas (FENAJ).

As duas pesquisas apontam que o vínculo de trabalho destes profissionais sofreu grandes transformações nas últimas décadas, como o aumento no número dos contratos de trabalho por projetos ou por tempo determinado (os freelancers), a exigência pela apresentação de notas fiscais de empresas jurídicas (ou PJ), além da propagação de um discurso em prol do empreendedorismo, entre outras formas de redução do contrato de trabalho com registro em carteira. Tais mudanças trouxeram como consequência a perda de direitos trabalhistas, 
como gozo de férias, FGTS e reajuste por acordo coletivo, entre outros. Além disso, a cada ano amplia-se a redução do número de vagas oferecidas aos jovens recém-formados, obrigando-os a encontrarem novos locais, formas e métodos de trabalho.

Fonseca e Souza (2006) consideram que o jornalismo brasileiro passou pelo pós-fordismo nas redações, onde a reestruturação do modo de produção capitalista tem implicações sobre a organização do trabalho no jornalismo industrial. Para eles, a transição para o regime flexível de acumulação, iniciada a partir de 1973 entre os países capitalistas avançados, aconteceu no Brasil apenas nos anos 1990, quando o avanço tecnológico e a internet já faziam parte da reestruturação do capitalismo, o que é coerente com a lógica capitalista de acumulação. Nessa época, com a chegada da internet, da informação eletrônica e interativa, mas, principalmente, com a informatização das redações, houve um rápido processo de transformação no mundo do trabalho desses profissionais.

Essas mudanças também foram comprovadas em outra pesquisa feita pelo CPCT-ECA/USP, Comunicação e Trabalho: as mudanças no mundo do trabalho nas empresas de comunicação (Figaro, 2008), que mostrou, em suas conclusões, que o mercado de trabalho para o comunicador exige um profissional com diversas habilidades em multiplataforma; também com noções de marketing e de administração, visto que se prioriza o consumidor e os públicos mais diversos. Sobre as relações de trabalho, a pesquisa apontou que elas ficaram mais competitivas, e nem sempre com respaldo em valores éticos, pois a concorrência e as condições contratuais precárias deixaram os profissionais em situação de desvantagem.

Para os comunicadores, não há dúvidas de que as novas mídias trouxeram maior agilidade. Alargaram a noção de notícia em tempo real que o rádio inaugurou e a televisão se esforça por desempenhar. A informação em tempo real do Twitter, do blog, do Facebook e do celular tem especificidade e conta com um novo protagonista, o cidadão comum, testemunha do fato, que alerta com sua mensagem de texto, imagem ou som, a comunidade e os meios de comunicação sobre o acontecimento. Trouxeram também os embates geracionais entre os jovens nascidos na era da internet, os nativos digitais (Prensky, 2001) e os imigrantes digitais, jornalistas maduros que precisaram se adaptar à polivalência dos novos tempos.

O jornalismo on-line, os blogs e as ferramentas das redes sociais são inovações nas rotinas profissionais que foram incorporadas e também adotadas como alternativas pelos jornalistas. A pesquisa O perfil do jornalista e os discursos sobre o jornalismo - Um estudo das mudanças no mundo do trabalho do jornalista profissional em São Paulo (Figaro, 2012) mostrou que as redes sociais têm sido 
uma ferramenta de trabalho importante para os jornalistas. Para buscar fontes, informações de pessoas, famosos, celebridades e até desconhecidos, utiliza-se como aliado o Facebook, o Linkedin e o Twitter, ferramentas que tornaram muitas agendas obsoletas. A notícia em tempo real do webjornalismo, do blog, está à frente da notícia que circula nos demais veículos e também em relação ao poder que hoje uma parcela da população tem de contestar, de criticar, ou de "furar" as empresas de comunicação.

\section{Jornalistas: das mudanças no mundo do trabalho à busca por novos arranjos}

A pesquisa do CPCT (Figaro, 2012) aponta que quase todos os jornalistas declararam nas entrevistas da fase qualitativa "ter um blog", geralmente relacionado à área cultural e de entretenimento. Segundo os entrevistados, o prazer está em ir ao futebol, cinema, teatro, shows, ouvir música ou ler um livro e escrever o comentário no blog. Não importa o dia ou horário, pode ser à noite, depois do expediente, ou num final de semana. O blog também é visto como uma vitrine e uma grande oportunidade profissional para se chegar a uma redação de jornal.

Os blogs causam verdadeiro fascínio para os jornalistas, seja pela sensação de liberdade que o meio promove, pela revitalização que trouxe à profissão, ou pela mudança na produção e na plataforma discursiva do jornalismo. No blog, o jornalista escreve sobre o que gosta, assume integralmente o papel de formador de opinião, com a possibilidade de aprofundar a notícia; ele pode simplesmente compartilhar um texto nas redes sociais; tem a instantaneidade e rapidez da internet a seu favor e ainda conta com o feedback do leitor/receptor. Para Martino (2009, p. 271), "os blogs desestabilizam algumas certezas da prática jornalística e colocam em questão algumas ideias consagradas a respeito do interior da profissão, de um lado, e da amplitude dos efeitos do jornalismo no espaço público, de outro".

Entre as inovações trazidas pelo blog, está o fato de que o jornalista não precisa da estrutura de uma empresa para se comunicar; tem a possibilidade de escrever de qualquer local e, principalmente com isenção, sem a interferência de interesses comerciais e/ou das empresas de comunicação, ideais que, a princípio, remetem à realização de um sonho. Nessa condição, o jornalista se vê como um empreendedor social, "uma alegoria do trabalhador imaginado pelo sistema capitalista, que integra a vocação, no sentido weberiano; a habilidade empreendedora; a capacidade de ser sustentável, no sentido econômico; e 
uma imagem de felicidade e realização plena" (Casaqui, 2015, p. 187). Para o autor, essa seria "a intersecção entre a dimensão comunicacional que constitui o espírito do capitalismo contemporâneo e significados atribuídos ao mundo do trabalho, à cultura corporativa" (Casaqui, 2015, p.187).

O perfil dos jornalistas blogueiros da pesquisa mostrou que, de modo geral, os quinze selecionados são profissionais maduros; tinham entre 39 anos (Leonardo Sakamoto) e 74 anos (Paulo Henrique Amorim) e uma carreira já consolidada no jornalismo, o que comprovou a hipótese de que reputação, popularidade, credibilidade e visibilidade são valores fundamentais (Recuero, 2009; Dantas, 2014) para a consolidação profissional na Sociedade em Rede (Castells).

Geograficamente, a maioria dos blogueiros selecionados está situada em São Paulo, região que mantém 30\% dos jornalistas brasileiros. O jornalista Altino Machado, do Acre, foi selecionado por ser, reconhecidamente por outros jornalistas, como um dos legítimos representantes, ao lado de Lúcio Flávio Pinto, do Pará, de uma região que é pouco ou nada divulgada pela grande mídia. Além de Altino, o jornalista Ricardo Noblat está situado em Brasília, e Miguel do Rosário no Rio de Janeiro. A seguir, estão alguns comentários e análises coletados a partir das entrevistas com os jornalistas blogueiros:

\section{a) Por que ter um blog}

A motivação dos jornalistas para criarem o próprio blog é bastante variada. As falas mais recorrentes afirmam que o blog foi adotado por indicação de pessoas mais jovens; por fazerem questão de estarem atualizados tecnologicamente; e ainda pela possibilidade de gerar uma informação diferenciada daquela publicada na grande mídia. Guazina $(2013$, p. 11) afirma que, para esses jornalistas, "o blog foi uma forma de conciliar com mais liberdade o exercício da profissão jornalística com a percepção sobre o mundo social, a política e o próprio jornalismo".

Os jornalistas brasileiros, principalmente aqueles ligados à política, passaram a dedicar mais tempo e empenho em suas publicações e também a conquistar mais leitores a partir de 2005, época do surgimento das primeiras denúncias do"mensalão", além do início da campanha eleitoral para a presidência da república, em 2006 (Darbilly, 2014). Houve, nessa época, uma clara polarização política da imprensa. Segundo Silveira (2007, p. 180), os blogs se tornaram importantes nessa época porque foram utilizados como munição de campanha contra a maioria dos veículos da grande imprensa e das notícias de TV, que "optaram, ora sutil, ora claramente, por uma postura favorável à candidatura 
oposicionista, e tiveram sua cobertura e suas edições filtradas e muitas vezes combatidas por diversos blogueiros". É a partir desse momento que ocorre, segundo Guazina (2013, p. 11), maior participação política desses profissionais, principalmente entre aqueles que não se alinhavam com o posicionamento dos grandes grupos de comunicação do qual faziam parte. Para ela, "o blog foi uma forma de conciliar com mais liberdade o exercício da profissão jornalística com a percepção sobre o mundo social, a política e o próprio jornalismo", completa.

\section{b) Como trabalham os blogueiros}

"Eu escrevo de casa, na calma da minha casa; às vezes escrevo de madrugada, acompanhado de uma cachaça ou copo de uísque. " (Borges, citado por Lima, 2015, p. 175). Ao fazer essa afirmação, o blogueiro independente Miro demonstra claramente que, para ele, o momento de escrever no blog, é um momento de prazer; ele escreve como se estivesse sentado em uma mesa de bar, degustando do seu aperitivo, sem ter a pressão de alguém ou do tempo para incomodar.

Trabalhadores compulsivos, Luís Nassif e Paulo Henrique Amorim estão constantemente conectados; demonstram em seus enunciados que mantém uma visão mais profissional do ato de bloggar; o primeiro, mantém uma empresa paralela ao blog, e utiliza um funcionário dessa empresa para auxiliá-lo; mas dedica-se também a escrever e selecionar comentários em casa, inclusive nos finais de semana. Ao afirmar que "isso me toma um tempo danado", demonstra um certo desconforto ao levar trabalho para casa. Ao mesmo tempo, planeja montar uma estrutura "para sobrar tempo para outras coisas também", ou seja, mais trabalho. Paulo Henrique Amorim divide o blog Conversa Afiada com o cargo de apresentador de um programa semanal na TV Record; sua fala também é bastante "profissional", de um jornalista que tem recursos, vê o blog como um negócio, e se preocupa em montar uma equipe para auxiliá-lo nessa empreitada.

"Gostaria de fazer mais reportagens, mas as pernas já não ajudam. Sim, repórteres dependem muito das pernas para chegar aos lugares onde as coisas estão acontecendo." (Kotscho, citado por Lima, 2015, p. 177). O enunciado de Ricardo Kotscho, 66 anos, é de um profissional que, embora seja um migrante da comunicação, pois está escrevendo para um novo meio digital e aprendendo novos saberes, é fiel ao ethos do jornalista, aquele que traz consigo os valores da profissão e produz grandes reportagens. Para ele, repórteres não têm que ficar no escritório, e sim ir para a rua, "onde as coisas estão acontecendo". Tal afirmação vai de encontro à realidade das redações, onde os jornalistas fazem entrevistas por telefone ou por e-mail, não checam as notícias, ou simplesmente 
reproduzem os releases enviados pelas assessorias de imprensa, segundo dados baseados na pesquisa do CPCT (Figaro, 2012).

\title{
c) $O$ critério da notícia
}

Valores como a objetividade, a independência e a verdade do jornalismo foram estabelecidos, segundo Traquina, a partir da profissionalização (séculos XIX e XX) e da implantação de "normas que constroem os contornos de representações profissionais bem definidas do 'bom' ou 'mau' jornalista" (2012, p. 204). Ao observar o trabalho dos jornalistas blogueiros, verificamos que estes profissionais levam para o blog os mesmos valores apreendidos ao longo da carreira nos veículos tradicionais, mantendo o seu ethos, e até mesmo estabelecendo uma rotina de trabalho semelhante à que mantinham nas redações.

\begin{abstract}
Então, quer dizer, a escolha que eu faço daqueles assuntos é muito o que eu, se estivesse numa redação de jornal, escolheria. Não vejo nenhuma diferença entre o que eu escolho ou o que eu escolheria, se estivesse trabalhando num jornal[...]. Meu critério pessoal, do que eu acho, como jornalista, que pode interessar aos leitores do blog. (Noblat, citado por Lima, 2015, p. 177)
\end{abstract}

Os valores-notícia são um aspecto fundamental da cultura profissional (Traquina, 2013). Ao afirmar diversas vezes que "eu faço" "o que eu escolheria", "do que eu acho", Noblat posiciona-se com a segurança de quem domina o conceito de noticiabilidade ${ }^{2}$; de quem toma as decisões e responde por elas, sem titubear, como fazia quando era editor de jornal. Paulo Henrique Amorim, no segundo enunciado, demonstra a mesma segurança; também traz como marca em suas falas sempre alguma crítica, além de manter um humor ácido, que carrega, inclusive, para os seus textos.

\section{d) A equipe e o tempo dedicados ao blog}

O trabalho do blogueiro é, quase sempre, solitário. Entre os jornalistas do grupo A (Dependentes), apenas Ricardo Noblat dispõe de um colaborador, que o auxilia no controle dos comentários dos leitores. Entre os jornalistas do grupo B (Independentes), Renato Rovai conta com apoio da equipe da revista

2 "Conjunto de critérios e operações que fornecem a aptidão de merecer um tratamento jornalístico, isto é, possuir valor como notícia". (Traquina, 2013, p. 61) 
Fórum, do mesmo portal; Luís Nassif também dispõe de um ajudante para os comentários do blog e da equipe de sua empresa; Luiz Carlos Azenha tem dois colaboradores para auxiliá-lo na administração do Viomundo; e Paulo Henrique Amorim tem uma equipe ("pequena e aguerrida", segundo ele) de quatro pessoas, sendo uma diretora executiva e uma administrativa e dois editores. Os demais escrevem e administram seus blogs sozinhos.

Noblat escreve o blog sozinho, mas sentiu necessidade de ter alguém para auxiliá-lo a controlar os comentários dos leitores. Encontrou esse colaborador entre os próprios leitores e, embora afirme remunerá-lo e tê-lo visto pessoalmente apenas uma vez, demonstra ter extrema confiança no trabalho dele, feito à distância, do Rio de Janeiro.

"Você tem limites que você se impõe, que são limites ligados ao estilo do jornalismo, de não baixar nível, de não recorrer a teorias conspiratórias, mas o blog sou eu e eu" (Nassif, citado por Lima, 2015, p. 179). Ao fazer essa afirmação, Nassif deixa claro que, embora ele tenha uma equipe para apoiá-lo, as decisões tomadas (e também as consequências) cabem, exclusivamente, a ele, que dá o nome e também a sua experiência e valores para o blog.

O tempo dedicado ao blog precisa ser conciliado com as demais tarefas do dia a dia: o outro emprego, os compromissos domésticos e familiares. 0 fato de poder publicar de qualquer lugar, desde que esteja conectado, faz com que os jornalistas acabem confundindo o tempo de trabalho com o tempo de lazer. Para Moreira (2009), a flexibilização e a intensificação do tempo de trabalho, ocorridas principalmente a partir dos anos 1990, trouxe, também uma flexibilização com os tempos de não trabalho, ou seja, o tempo fora dos locais de trabalho. Tal fato leva, segundo a autora, a algumas discussões a respeito do tempo livre. Trabalhar em casa, mesmo que fazendo o que se gosta, é lazer? E cuidar das tarefas domésticas nos momentos fora do tempo de trabalho? Ao considerar o trabalho como atividade humana, podemos afirmar que, mesmo que seja feito fora dos ambientes e horários normais, com ou sem satisfação, sozinho ou em grupo, é sempre trabalho.

\section{e) A relação com os leitores}

Ojornalista queveio do impresso raramente precisou ter um contato direto com o seu leitor. Nas antigas redações era possível apenas receber uma visita ou mesmo uma carta, que poderia ser reproduzida ou não no espaço destinado para publicação. Hoje a relação é direta e instantânea. Os leitores estão conectados e dispostos a participar do dia a dia dos noticiários, principalmente nos blogs. Elogiam, dão sugestões, mas também criticam e até ofendem os jornalistas. A 
sociedade em rede trouxe o melhor, mas também o pior lado da comunicação direta. Os jornalistas blogueiros precisaram criar novas prescrições aprender a lidar com essa mudança, que foi bastante impactante para o profissional.

Noblat demonstra certo orgulho por não filtrar comentários. Ele, que foi um dos pioneiros da blogosfera, aprendeu a lidar com os leitores a partir de tentativas de erros e acertos: impôs regras, cortou comentários, até concluir que era melhor colocar um mediador para cumprir esse papel. É interessante porque alguns jornalistas buscaram os blogs para ter mais independência, autonomia e liberdade de expressão. Mas foram, de certo modo, obrigados a controlar os comentários dos leitores, como explicou Borges em entrevista:

\begin{abstract}
Eu controlo os comentários, porque vem besteira de tudo que é lado, vem coisa machista, homofóbica. Eu não publico; ainda tem gente que brinca, tem muito comentário de direita, de muita raiva, xingamento, e aí eu me divirto porque o cara fala "eu duvido você publicar". Eu não tenho dúvida nenhuma e deleto o cara. (Borges, citado por Lima, 2014, p. 181)
\end{abstract}

Os comentários de leitores também são passíveis de processos judiciais, o que acarreta preocupação para os blogueiros. O Blog do Noblat está hospedado no portal Globo, tem um contrato com a empresa de comunicação, mas, caso alguém se sinta ofendido por algum comentário de leitor, processará o blogueiro e não a empresa que hospeda o blog. Por isso, cabe aqui, também, a extrema preocupação com o controle dos comentários. Vale notar que, embora a responsabilidade do blog seja de Noblat, seus textos estão alinhados ao pensamento da Rede Globo, ou seja, da mídia hegemônica. E, por esse motivo, talvez, não existam processos judiciais contra ele.

Evidentemente que todo comentário em blog pressupõe uma censura prévia. Você tem pessoas mal-intencionadas, racistas, pedófilos. Pessoas que defendem pleitos óbvios. Que entram no blog repetidas vezes com o objetivo de "dar pau" no blog. Isso aconteceu comigo na versão anterior. Então você tem que fazer uma seleção prévia. Todo mundo faz isso. Uma moderação. Na medida do possível, você deixa fazer com que estes comentários sejam os mais ecléticos e os mais plurais possíveis, mas sempre existe uma.... Quem entra no meu blog, em geral, é para concordar comigo. Quem gosta da Miriam Leitão não vai no meu blog (risos) (Amorim, citado por Lima, 2015, p. 181). 
Amorim vai direto ao ponto e fala em censura prévia, como a que era imposta na época da ditadura militar no Brasil. Depois ameniza a fala, mudando para "moderação". Embora ele afirme, bem-humorado, que "quem entra no meu blog, em geral, é para concordar comigo", não é o que ocorre. Amorim, como exposto em seu próprio blog, possui diversos processos judiciais contra ele na blogosfera, como é possível constatar em um espaço intitulado "não me calarão", disponível em seu blog. Ou seja, quem não concorda com ele, lê o blog. E o processa.

\section{f) A liberdade proporcionada pelo blog}

No jornalismo convencional nunca me senti livre. O jornalismo convencional é um jornalismo comercial. E quem disser que é livre mente. Não existe isso. Você é livre se você pensar como o patrão. No Brasil funciona assim: você tem toda a liberdade de pensar como o seu patrão pensa. Na internet sim [...]. Eu acho que, felizmente, a imprensa é tão medíocre que permitiu esse espaço de autonomia, espaço de liberdade (os blogs) (Amorim, citado por Lima, 2015, p. 183-184).

Paulo Henrique Amorim fala com segurança de um lugar privilegiado; de um profissional que passou por todas as grandes empresas de comunicação e entende profundamente da lógica política e econômica que rege o poder do jornalismo: "você é livre se você pensar como o patrão", afirma. Ou seja, se você se rende à lógica capitalista do lucro. Para o autor, os blogs só são considerados uma alternativa, por conta do controle das grandes empresas. Segundo sua lógica, se não existisse essa manipulação, esse controle, não haveria motivos para buscar outros meios independentes.

No blog eu até agora não tenho absolutamente do que me queixar. Tanto no contrato que eu fiz originalmente com o IG, depois de um tempo, como depois no Estadão, quando o blog foi pro Estadão, e no Globo. Faz parte do contrato que o conteúdo é responsabilidade minha, para o bem ou para o mal. Por exemplo, se eu sou processado, sou eu quem tenho que me defender. Não é o portal que me defende. Eu estou sendo processado pelo Renan (Calheiros). Isso sai do meu bolso. O Globo não tem nada a ver com isso. Em compensação, eu não consulto ninguém sobre o que eu publico ali dentro. $E$ até hoje, pelo menos, nem no Estadão, nem antes, no IG, nem agora no Globo, não tive nenhum problema, até agora. Espero não ter (Noblat, citado por Lima, 2015, p. 184). 
O blogueiro retoma o assunto, afirmando não ter do que se queixar em relação ao seu vínculo com o portal $O$ Globo. Seu posicionamento reforça o enunciado anterior, de Amorim. Noblat pensa como o patrão, então ele é livre para escrever o que quiser. Está ideologicamente alinhado ao pensamento hegemônico da Rede Globo.

\begin{abstract}
Não dizem que cada cabeça é uma sentença? Cada blogueiro é uma sentença né? É... Se você perguntar, se você fizer dez perguntas sobre temas polêmicos para dez blogueiros você vai ter dez respostas né? É... o que cada um pensa de forma diferente. Não tem muito o que une a blogosfera. O que acabou unificando a blogosfera foi uma defesa da liberdade de expressão. Eu quero me expressar! Liberdade de expressão no sentido profundo dela, não é liberdade de expressão de poucos. Eu quero me expressar, eu quero tuitar, eu quero tá na defesa da liberdade de expressão, a visão crítica sobre essa mídia tradicional é um terceiro ponto. A defesa dessa justiça social (Borges, citado por Darbilly, 2014, p. 179).
\end{abstract}

O enunciado de Borges o coloca na posição de jornalista e blogueiro independente de vínculos. Ele ressalta com veemência, que o que espera da blogosfera, não é um pensamento único, e sim a liberdade de expressar o pensamento que quiser. "Eu quero me expressar", diz ele, está em primeiro lugar entre seus objetivos. Depois está a defesa dessa liberdade e a crítica à mídia tradicional.

\title{
g) Os meios de subsistência
}

A questão da subsistência é essencial para qualquer pessoa, mas o trabalho do jornalista blogueiro traz, a nosso ver, algumas peculiaridades. Para a teoria do valor trabalho, de Marx, apenas os jornalistas pertencentes ao grupo A são considerados produtivos. Esses jornalistas mantêm contrato ou são funcionários de portais de grandes corporações de comunicação e, nessa condição, vendem a sua força de trabalho, produzindo lucro para essas empresas. Os jornalistas do grupo $B$, sob essa perspectiva, são considerados improdutivos, porque produzem a informação, não a vendem e, portanto, não trazem lucro, para si e nem para os outros. Já os jornalistas do mesmo grupo, que sobrevivem da venda de anúncios ou de outros tipos de lucro, mas que são voltados exclusivamente para a subsistência do blog e do jornalista, também são considerados improdutivos. Diante dessa lógica, como eles fazem para 
sobreviver diante da força e do poder dos grandes meios de comunicação, e ainda produzir informação diferenciada de qualidade?

Sem dúvida é o grande obstáculo. O Viomundo é mantido exclusivamente com a contribuição dos leitores e mais o próprio dinheiro que eu coloco no blog [...]. O blog é deficitário. Ele é financiado através e uma assinatura anual pelo valor de dez reais (Azenha, citado por Lima, 2015, p. 185).

Todos os jornalistas do grupo A têm posição financeira privilegiada diante dos demais. Os blogs de Josias de Souza, Juca Kfouri e Leonardo Sakamoto estão ligados ao portal UOL. Sakamoto ainda é coordenador da ONG Repórter Brasil e representante na Comissão Nacional para a Erradicação do Trabalho Escravo. Reinaldo Azevedo é, há muitos anos, funcionário do grupo Abril e seu blog está ligado ao portal da revista Veja; Ricardo Noblat está vinculado ao portal Globo, como já dissemos anteriormente, e Ricardo Kotscho manteve o Balaio do Kotscho independente até 2011, quando assinou um contrato de quatro anos com a TV Record para atuar como comentarista do Jornal Record News e também hospedar o seu blog no portal da emissora, o R7. Além dos contratos e vínculos empregatícios com essas empresas, esses jornalistas ainda têm a possibilidade de lucrar com os anúncios nas suas páginas. São grandes universidades, bancos, empresas de cartões de crédito, de comércio eletrônico, cosméticos e perfumes importados, empresas aéreas e do ramoimobiliário. Desse modo, esses profissionais não têm problemas financeiros, nem para comentar.

Os dois jornalistas blogueiros do enunciado acima optaram por não ter os seus blogs ligados a portais de grandes corporações da mídia. Por isso, pertencem ao grupo $B$ e consideram-se independentes. $E$, embora tenham outros empregos - Luiz Carlos Azenha é repórter e Paulo Henrique Amorim é apresentador, ambos na TV Record - eles se ressentem das dificuldades de manter um blog, seja com anunciantes ou com outros meios alternativos. Azenha, inclusive, não aceita o patrocínio de empresas ligadas ao governo, o que dificulta ainda mais o seu trabalho.

Embora seja um migrante da comunicação, um jornalista de origens da era romântica e engajada profissão, Amorim demonstra ser, ao lado de Luís Nassif, aquele que mais vê o blog como um negócio. Claro, a ideia de ter um meio alternativo e independente está presente nos seus atos e em suas falas, mas é possível notar também uma grande preocupação com a subsistência de seu veículo, considerado por ele como uma pequena empresa de comunicação. 
"Quem entra nessa guerra, na linha de frente, só tem a perder. Porque primeiro vai ter um receio geral dos patrocinadores, e qualquer patrocínio que vier, vão imputar a essa guerra. É complicado" (Nassif, citado por Lima, 2015, p. 189). O enunciado de Luís Nassif mostra as dificuldades encontradas pelos blogueiros para manter um posicionamento ideológico e político alinhado com os anunciantes. Uma das discussões entre blogueiros que se consideram independentes é se devem ou não aceitar anúncios publicitários do governo, seja municipal, estadual ou federal. Para alguns jornalistas, tais anúncios tirariam a autonomia e a independência mediante críticas e reportagens contrárias. Outros, como o próprio Nassif, não vêm problemas e fazem contratos milionários. Em compensação, estão sujeitos a cortes e atrasos.

\section{Os arranjos econômicos alternativos: o crowdfunding e o colaborativismo}

Quase todos os blogueiros independentes adotaram o crowdfunding para ajudar na subsistência. Segundo eles, a quantidade de leitores assinantes ou colaboradores ainda está longe do ideal, mas a aceitação das pessoas ao método demonstra o grande interesse dos leitores por uma informação imparcial, por opinião e por uma boa reportagem investigativa. Com o financiamento coletivo, o poder sai das mãos dos grandes grupos de comunicação e passa para outros financiadores, ou seja, os leitores.

Recentemente, a migração de jornalistas se acentuou, com jornalistas oriundos de grandes grupos de comunicação que partem para experiências em coletivos de jornalistas. Trata-se de um novo arranjo econômico alternativo, apropriado por jornalistas interessados em contrapor-se aos grandes meios de comunicação hegemônicos. Baseados no colaborativismo, ou criação colaborativa, os coletivos de jornalistas propõem a produção de conteúdo de forma colaborativa. Segundo Malini e Antoun (2013, p.115), já existem há algum tempo diversas experiências, "que atuam de forma independente através de modelo aberto (sem a presença de jornalistas profissionais) ou híbrido (usuários e jornalistas profissionais), inventando um conjunto de novas práticas para a produção noticiosa".

A partir de 2013 surgiram novas propostas, totalmente focadas no jornalismo independente, como A Ponte - Segurança Pública, Justiça e Direitos Humanos, criada em 2014 com jornalistas oriundos da grande mídia como André Caramante, Bruno Paes Manso e Laura Capriglione, entre outros e a Agência Pública de Jornalismo Investigativo, a pioneira no modelo de jornalismo sem fins lucrativos para manter a independência, fundada por Marina Amaral, Natália Viana e Tatiana Merlino. Em 2015, surge o coletivo "Jornalistas Livres", entre 
outros que seguiram o mesmo modelo a partir de então. Esses exemplos de arranjos econômicos não são novos; são modelos inspirados no cooperativismo e no jornalismo alternativo, que foram adaptados à sociedade em rede e (re) apropriados pelos jornalistas. Mas servem para demonstrar o quanto é fértil a busca por alternativas nesse momento, de surgimento de novos meios e, ao mesmo tempo, de crise no jornalismo.

Do ponto de vista ergológico, é a atividade de comunicação e trabalho que orienta o olhar para o jornalista e seus embates à procura de alternativas para a realização plena de si no trabalho. O profissional busca fugir das relações alienantes que lhe impedem de ter as decisões sobre todo o processo de seu trabalho, e o embate entre o prescrito, as normas antecedentes e o trabalho real vão reinventando um modo de fazer jornalismo. Invenção que, nem bem ganha a luz da existência, já se depara com os desafios do sistema do capital: sobreviver às dificuldades econômicas, aos esquemas de controle, vigilância e censura.

\section{Considerações finais}

Já se passaram mais de dez anos desde que os jornalistas adotaram os blogs como veículo de comunicação no Brasil. Durante o período, esses profissionais migraram para o novo meio e enfrentaram diversos obstáculos, como a adaptação às rotinas produtivas, às novas prescrições e também às formas de sobrevivência, sustentabilidade e manutenção do veículo. Se, conforme a afirmação de Williams (2011), os jornalistas têm os meios de produção, eles também têm os meios de comunicação. Mas quem tem os meios de comunicação também detém o poder? Nem sempre. Aos analisarmos o grupo selecionado pelo viés econômico, verificamos inicialmente que os jornalistas blogueiros que estão ligados aos portais de empresas de comunicação, e também aqueles que ainda mantém o emprego na grade mídia, estão em situação privilegiada em relação ao demais. $E$ justamente aqueles que querem fazer um jornalismo que se contraponha ao que é feito pelas empresas de comunicação não têm o apoio financeiro necessário para se manter. Esse problema é um dos reflexos da concentração de mídia ${ }^{3}$ que ocorre no Brasil.

A pesquisa, portanto, chega a conclusões contundentes em relação aos jornalistas blogueiros. A primeira delas é que a total independência e liberdade de expressão desejada pelos blogueiros é ilusória. Como sobreviver, dentro da lógica capitalista, sem um meio de subsistência? Além da difícil

3 Mídia aqui, segundo a definição de Lima (2006, p.52), "refere-se à indústria da cultura, isto é, às emissoras de rádio e de televisão (aberta e paga), aos jornais, às revistas e ao cinema, portadores do que se chama de comunicação de massa". Incluímos aqui, diferentemente do autor, a internet. 
relação com os anunciantes, há falta de uma legislação específica, que deixa brechas para medidas judicias e cerceamento econômico contra os jornalistas blogueiros. A segunda, a censura passa a ser controlada por decisões judiciais. Consequentemente, aqueles que têm mais recursos conseguem sobreviver ao enfrentamento com a justiça; aos demais, resta procurar apoio, novas soluções, ou simplesmente encerrar o blog e voltar ao silêncio. A terceira, a estabilidade financeira está no vínculo com as empresas de comunicação, e a dificuldade econômica e jurídica desses arranjos econômicos se constitui no desafio de se manterem com seu discurso contra-hegemônico.

A sociedade em rede nos mostra que a internet é um espaço privilegiado de luta política para a sociedade civil; mas, na mesma proporção que surgem movimentos em prol da democracia e da liberdade de expressão, nascem organizações contrárias, de incitação ao ódio e desrespeito aos direitos humanos, além de uma preocupação constante em torno do controle e da censura. O embate do jornalista com o leitor agora é direto, e ambos têm o poder de disseminar a informação nas redes sociais ou nos próprios blogs, mas apenas os jornalistas de maior fama e tempo de carreira conseguem se manter. $O$ jornalista está, enfim, em constante adaptação aos novos desafios da profissão.

\section{REFERÊNCIAS}

ANTUNES, Ricardo. Adeus ao trabalho? Ensaio sobre as Metamorfoses e a Centralidade do Mundo do Trabalho. São Paulo: Cortez Editora, 1995.

BIANCHI, Felipe; BORGES, Altamiro. Blogueir@s, uni-vos (mas nem tanto). São Paulo: Centro de Mídia Barão de Itararé, 2014.

BRIGGS, Asa\& BURKE, Peter. Uma história social da mídia: de Gutenberg à Internet. 2 ed. Rio de Janeiro: Jorge Zahar Editor, 2006.

CASAQUI, Vander. Empreendedorismo social em perspectiva global: bem comum, trabalho e engajamento na retórica do capitalismo contemporâneo. Revista Eletrônica Internacional de Economia Política da Informação, da Comunicação e da Cultura (EPTIC), Aracaju, v. 17, n. 1, p. 185-198, jan. 2015. Disponível em: https://seer.ufs.br/index.php/eptic/article/view/3383/pdf Acesso em: 02 abr. 2017.

DANTAS, M.; CANAVARRO, M.; BARROS, M. Trabalho gratuito nas redes: de como o ativismo de $99 \%$ pode gerar ainda mais lucros para $1 \%$ ? Liinc em revista, v. 10, n. 1, 2014. Disponível em: http://www.brapci.ufpr.br/brapci/v/a/16017. Acesso em: 25 Jul 2017. 
DARBILLY, Leonardo Vasconcelos Cavalier. Blogosfera, estratégias de subversão e o campo da comunicação no Brasil: uma análise do Movimento dos Blogueiros Progressistas sob uma perspectiva de estudos organizacionais. 2014, $297 \mathrm{f}$. Tese (doutorado). Escola Brasileira de Administração Pública e de Empresas da Fundação Getúlio Vargas (FGV), São Paulo, 2014.

FIGARO, Roseli (coord.); NONATO, Claudia; GROHMANN, Rafael. As mudanças no mundo do trabalho do jornalista. Prefácio de José Marques de Melo. São Paulo: Atlas, 2013.

(coord.). O perfil do jornalista e os discursos sobre o jornalismo: um estudo das mudanças no mundo do trabalho do jornalista profissional em São Paulo. Centro de Pesquisa em Comunicação e Trabalho CNPq/ECA-USP. São Paulo: Fapesp, 2012. Pesquisa concluída. Disponível em: http://www.eca.usp.br/ comunicacaoetrabalho/wp/index.php/pesquisas/2009-2012/. Acesso em: 02 abr. 2017.

(coord.). Comunicação e trabalho: as mudanças no mundo do trabalho nas empresas de comunicação. Centro de Pesquisa em Comunicação e Trabalho CNPq/ECA-USP. São Paulo: Fapesp, 2008. Pesquisa concluída. Disponível em: http://www2.eca.usp.br/comunicacaoetrabalho/wp/index.php/pesquisas/ 2005-2007/. Acesso em: 24 de jul. de 2017.

FONSECA, Virgínia e SOUZA, Paulo H. Rodrigues de. O pós-fordismo na produção jornalística. Revista Intexto, Porto Alegre: UFRGS, v. 2, n. 15. p. 1-18, jul. 2006. Disponível em: http://www.seer.ufrgs.br/index.php/intexto/article/ view/4264/4426. Acesso em: 02 abr. 2017.

GUAZINA, Liziane Soares. Jornalismo que tem lado: o caso dos blogueiros brasileiros "progressistas". Revista Brazilian Journalism Research - v. 9 - n. 2 - p. 6887, dez. 2013. Disponível em: http://bjr.sbpjor.org.br/bjr/article/view/545/492 Acesso em 02 abr. 2017.

HARVEY, David. Condição Pós-Moderna. São Paulo: edições Loyola, 1996.

LIMA, Cláudia do Carmo Nonato. Jornalistas, blogueiros, migrantes da comunicação: em busca de novos arranjos econômicos para o trabalho jornalístico com maior autonomia e liberdade de expressão. 2015. Tese (Doutorado em Teoria e Pesquisa em Comunicação) - Escola de Comunicações e Artes, Universidade de São Paulo, São Paulo, 2015.

Comunicação e mundo do trabalho do jornalista: o perfil dos jornalistas de São Paulo a partir da reconfiguração dos processos produtivos da informação. 2010. Dissertação (Mestrado em Teoria e Pesquisa em Comunicação) - Escola de Comunicações e Artes, Universidade de São Paulo, São Paulo, 2010. 
Do Impresso aos blogs: a busca de jornalistas pela liberdade de expressão em novos métodos e processos produtivos. In STRELOW, A; FILHA, E; Pena, F; ASSIS, F; COUTINHO, I. (Orgs.). Jornalismo: História, Teorias, Gêneros e Práticas. São Paulo: Intercom, 2012.

LIMA, Venício. Mídia. Crise política e poder no Brasil. São Paulo: Editora Fundação Perseu Abramo, 2006.

MALINI, Fábio; ANTOUN, Henrique. @ Internet e \# Rua. Ciberativismo e mobilização nas redes sociais. Porto Alegre: Sulina, 2013.

MARTINO, Luís Mauro Sá. Teoria da Comunicação: ideias, conceitos e métodos. Petrópolis, RJ: Vozes, 2009.

MICK, Jacques (Org.); BERGAMO, Alexandre; LIMA, Samuel. Perfil do jornalista brasileiro. Características demográficas, políticas e do trabalho. Síntese dos principais resultados, 2012. Disponível em: http://perfildojornalista.ufsc.br/. Acesso em 16 mai. 2017

MOREIRA, Sonia Virginia. Análise documental como método e como técnica. In DUARTE, J.; BARROS, A. (Org.). Métodos e técnicas de pesquisa em comunicação. São Paulo: Atlas, 2015.

ORTIZ, Renato. Mundialização e cultura. São Paulo: Brasiliense, 2000.

PRENSKY, Marc. Nativos Digitais, Imigrantes Digitais. On the Horizon (NCB University Press, vol. 9 n. 5, outubro 2001). Disponível em: http://www.colegiongeracao. com.br/novageracao/2_intencoes/nativos.pdf Acesso em 02 abr. 2017.

PRIMO, Alex. Blogs e seus gêneros: avaliação estatística de 50 blogs em língua portuguesa. Revista Matrizes - ECA/USP. v. 4; n. 1; p. 129-147, dez. 2010. Disponível em: http://periodicos.usp.br/matrizes/article/view/38281/41095. Acesso em: 02 abr. 2017.

RECUERO, Raquel. Redes sociais na internet. Porto Alegre: Sulina, 2009.

SCHWARTZ, Y. e DURRIVE, L. (Orgs.). Trabalho e Ergologia. Conversas sobre a atividade humana. Tradução de Jussara Brito e Milton Athayde. Niterói: EdUFF, 2003 (1ed.); 2007 ( 2 ed.)

SILVEIRA, Sérgio Amaral da. Combates na fronteira eletrônica: a internet as eleições de 2006. In: LIMA, V. (Org.). A mídia nas eleições de 2006. São Paulo: Editora Fundação Perseu Abramo, 2007.

THOMPSON, John. A mídia e a modernidade. Uma teoria social da mídia. 15a ed. Petrópolis, RJ: Vozes, 2014.

TRAQUINA, Nelson. Teorias do Jornalismo volume I. Porque as notícias são como são. 3 ed. Florianópolis: Insular. rev. 2012. 
Teorias do Jornalismo volume II. A tribo jornalística - uma comunidade interpretativa transnacional. Florianópolis: Insular. rev. 2013.3 ed.

WOLTON, Dominique. Internet, e depois? Uma teoria crítica das novas mídias; tradução Isabel Crossetti. 3 ed. Porto Alegre: Sulina, 2012.

WILLIAMS, Raymond. Cultura e Materialismo. São Paulo, Editora Unesp, 2011.

Recebido em: 27/7/2017

Aceito em: 3/8/2017

Dados da autora:

Cláudia Nonato | claudia.nonato@uol.com.br

Doutora e mestre em Ciências da Comunicação pela ECA-USP, professora do Mestrado Profissional em

Jornalismo do FIAM-FAAM Centro Universitário, pesquisadora do Centro de Pesquisa em Comunicação e

e Trabalho (CPCT/ ECA-USP), Editora Executiva da Revista Comunicação \& Educação (ECA-USP) e Diretora

Administrativa da SBPJor (Gestão 2017-2019).

FIAM-FAAM Centro Universitário

Rua Vergueiro 101

CEP 04272-000 - São Paulo (SP) - Brasil 